\title{
Simposio
}

\section{El Residentado Médico en el Perú}

\section{The Medical Residency in Perú \\ Introducción}

\author{
Introduction
}

Oscar G. Pamo-Reynal

\section{Resumen}

Desde que se inició el residentado médico en el Perú, en 1952, han ocurrido una serie de cambios que han devenido en un sistema cada vez más integrado. Actualmente, el Ministerio de Salud, que es el principal soporte del residentado médico, trata de suplir las necesidades de especialistas médicos con un concurso único anual a través de CONAREME, que es el órgano directivo del Sistema Nacional de Residentado Médico. Se presentan las fortalezas, oportunidades, amenazas y debilidades del residentado médico en nuestro país.

Palabras clave: Residentado médico, medicina, educación médica, posgrado, especialización.

\section{Abtract}

Since the start of medical residency in Peru, in 1952, there have been a number of changes that have become an increasingly integrated system. Currently, the Ministry of Health, which is the main support of medical residency, tries to meet the needs of medical specialists with a single annual competition through CONAREME, which is the management board of the National Medical Residency System. The strengths, opportunities, threats and weaknesses of the medical residency in our country are presented.

Keywords: Medical residency, medicine, medical education, postgraduate, specialization.

El residentado médico es el sistema por el cual un médico adquiere las competencias en determinada especialidad o subespecialidad de la medicina. El objetivo debe alcanzarse en un tiempo determinado, que en la gran mayoría dura tres años pero en algunos casos pueden ser cuatro o cinco años, siguiendo un programa académico desarrollado por una facultad de medicina.

El residentado médico se inició en 1952 en nuestro país pero recién desde 1963 tuvo una formación académica; y, desde 1974 se tuvo una formación escolarizada y otra no escolarizada.

En 1976 se creó el Sistema Nacional de Residentado Médico (SINAREME). En 2017 se dio la Ley N 30453, Ley del Sistema Nacional de Residentado Médico y su Reglamento. Por esta Ley se creó el Consejo Nacional de Residentado Médico (CONAREME) que es el órgano directivo del Sistema Nacional de Residentado Médico.
La formación de los especialistas se realiza principalmente en los hospitales del Ministerio de Salud (MINSA), EsSalud, Fuerzas Armadas y Policiales y clínicas privadas merced a convenios específicos. La modalidad de enseñanza es la docencia en servicio. Los médicos residentes tienen una condición de alumno de posgrado en la facultad de medicina a la cual aplicaron, y un contrato con la institución prestadora de los servicios de salud donde realizan el residentado.

El crecimiento de la población y la creación de nuevos hospitales a nivel nacional ha puesto en evidencia la carencia de recursos humanos de salud.

Un breve análisis de lo que es el residentado médico en nuestro país nos llevaría a las siguientes consideraciones.

${ }^{l}$ Médico internista. Director de la Unidad de Posgrado y Especialización, Facultad de Medicina, Universidad Peruana Cayetano Heredia. 


\section{Oportunidades}

- Falta de especialistas en el país. En efecto, existe una brecha entre el número de especialistas que se requiere actualmente en el país (déficit) y el número de especialistas en ejercicio (oferta) ${ }^{1}$ (Cuadro 1 ).

El déficit de especialistas ha disminuido casi un 5\% en los últimos diez años pero todavía es patente la brecha. Además de la falta de especialistas, la distribución de los mismos es desigual; esto es, Lima ciudad sigue concentrando a casi el $70 \%$ de los médicos del país. Las regiones con mayor pobreza del

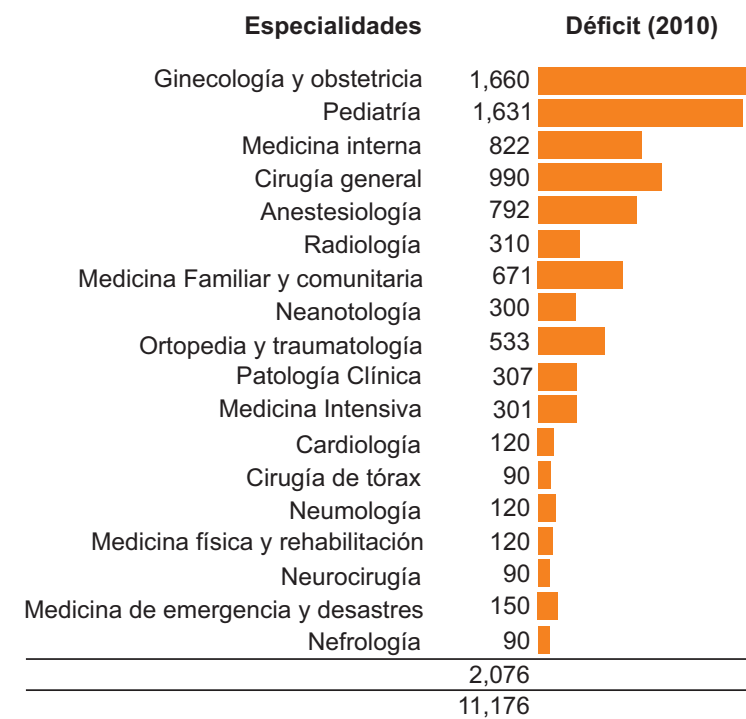

país como el trapecio andino y la subregión nororiental son las más desatendidas.

Para atenuar la brecha de la necesidad de especialistas, el MINSA ha venido incrementando el número de plazas ofertadas en las diferentes especialidades, siguiendo sobre todo las consideradas como prioritarias. Las plazas se adjudican a través de un examen único anual, con excepción de, en los años 2014 y 2015 en que se convocó a dos concursos por año con tal fin. Las plazas o vacantes son libres, por destaque y cautivas ${ }^{2}$.

Veamos las vacantes ofertadas (Cuadro 2).

Fuente: MINSA

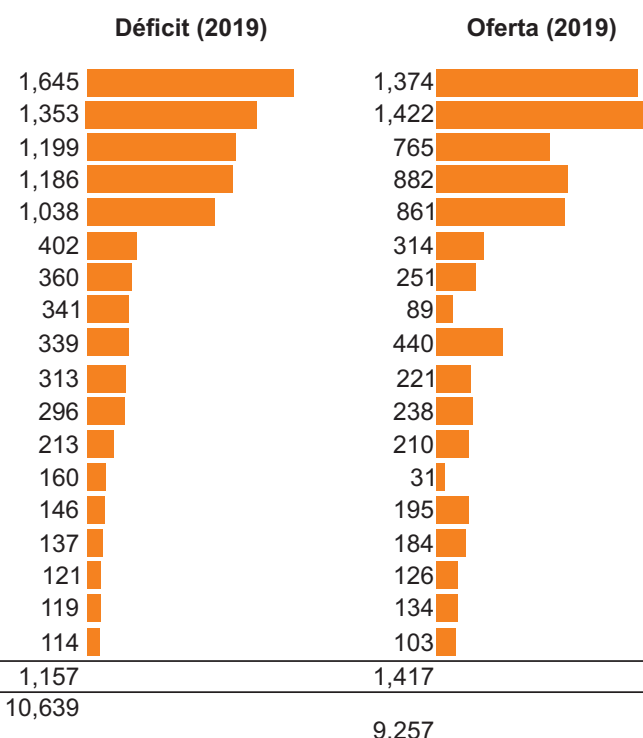

9,257

Cuadro 1. Oferta y demanda de médicos especialistas (Minsa + regiones),

\begin{tabular}{|ccccccccc|}
\hline Institución & 2013 & 2014 & 2015 & 2016 & 2017 & 2018 & 2019 & $\begin{array}{c}\text { Total } \\
\text { general }\end{array}$ \\
EsSalud & 844 & 849 & 850 & 850 & 850 & 850 & 850 & 5943 \\
MINSA & 1389 & 2220 & 2198 & 1499 & 1552 & 1764 & 1848 & 12470 \\
Otros & 35 & 62 & 55 & 48 & 30 & 44 & 27 & 301 \\
Sanidades & 241 & 296 & 212 & 212 & 208 & 196 & 180 & 1545 \\
Total general & 2509 & 3427 & 3315 & 2609 & 2640 & 2854 & 2905 & 20259
\end{tabular}

Cuadro 2. Vacantes ofertadas por institución y concurso de admisión 2013-2019.

\footnotetext{
${ }^{1}$ MINSA. Reproducido del diario La República, 28 de julio del 2019, página 21.

${ }^{2}$ Según las Disposiciones Complementarias de CONAREME (Decreto Supremo 008-88-SA) se tiene las siguientes definiciones: Vacante Libre: Es aquella vacante financiada por una entidad prestadora de servicios de salud pública o privada.

Vacante por Destaque: Es aquella vacante a la que postula un médico con vínculo laboral público (nombrado, efectivo o su equivalente) quien debe cumplir con los requisitos exigidos por su respectiva institución: Ministerio de Salud, EsSalud, Gobiernos Regionales, Sanidades de las Fuerzas Armadas y Sanidad de la Policía Nacional del Perú y otras Instituciones de Salud del sector público.

Vacante Cautiva: Es aquella vacante destinada exclusivamente a médicos cirujanos que pertenecen a la misma entidad o institución que ofrece la vacante, con excepción de los médicos de los gobiernos regionales, quienes podrán acceder a una vacante cautiva del Ministerio de Salud y sus organismos públicos.
} 


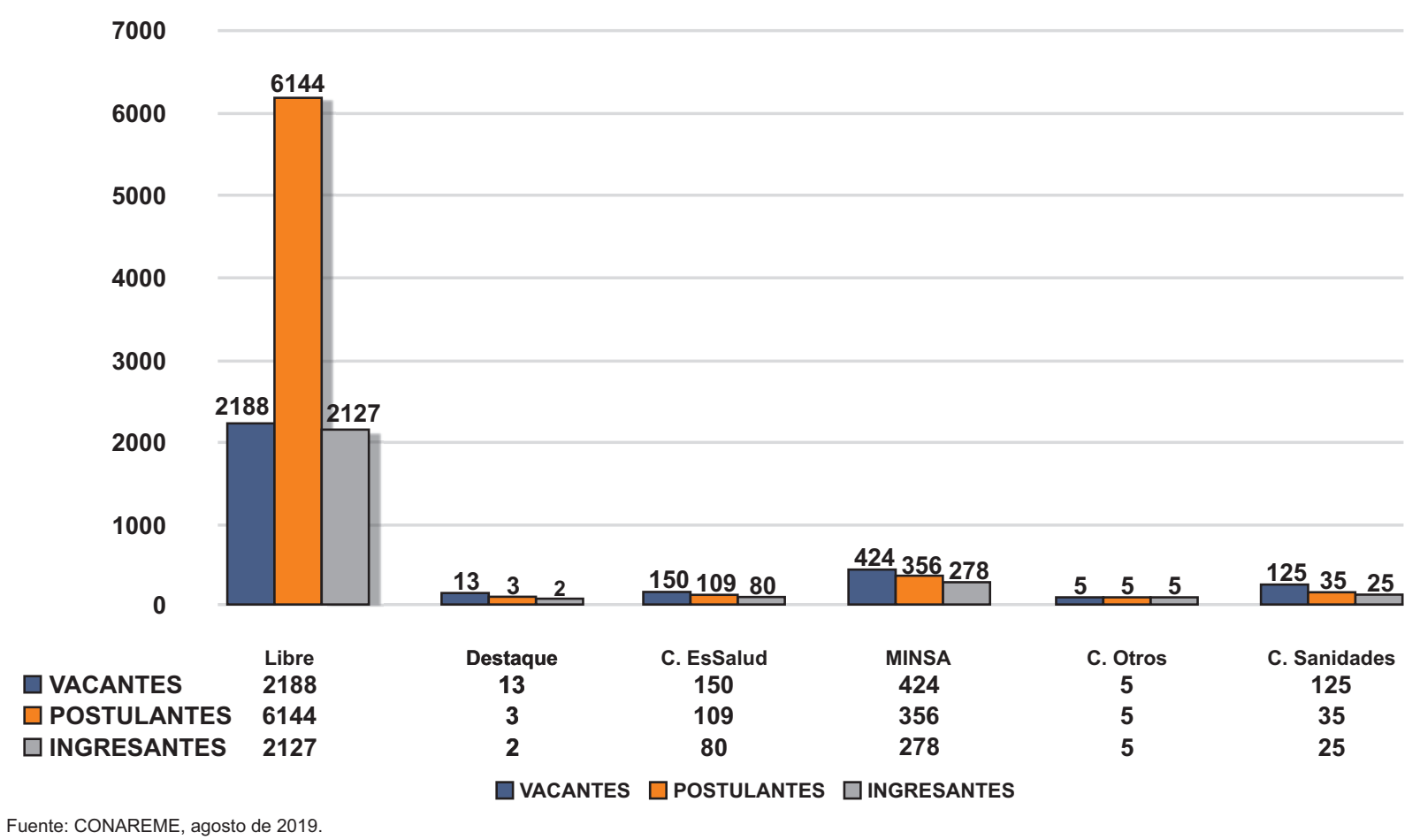

Fuente: CONAREME, agosto de 2019.

Cuadro 3. Vacantes postulantes e ingresantes 2019.

El interés por los médicos de ingresar al residentado lo podemos calcular: número de postulantes (6 144) entre las vavacantes ofrecidas (2 188), lo que nos da una relación de 2,8 postulantes por vacante, la que varía de acuerdo a la especialidad.

La adjudicación de las plazas cautivas y por destaque fue en menor proporción que las adjudicadas a los postulantes de las plazas libre (Cuadro 3 ).

Debemos recalcar que no solo faltan médicos especialistas en el país sino también los otros profesionales de la salud como enfermeros, tecnólogos médicos, etc. Esto es importante porque el ejercicio de la medicina moderna se lleva a cabo como un equipo de trabajo.

\section{Amenazas}

- Presupuesto del MINSA insuficiente. El presupuesto destinado a salud se ha incrementado en los últimos años, en 2016 fue de 7430 millones de soles y en 2019 es de 9524 millones de soles, pero resulta insuficiente para cubrir la mayoría de las necesidades de infraestructura, equipamiento, medicamentos, etc., además de los recursos humanos ${ }^{3}$. Un presupuesto insuficiente no permitirá subvencionar la formación de especialistas en el país.

- Diferentes sistemas de salud en cuyas instituciones se realiza el residentado (MINSA, EsSalud, Fuerzas Armadas, Fuerzas Policiales, Clínicas Privadas). La heterogeneidad de los establecimientos pertenecientes a los diferentes sistemas de salud impide homogenizar la docencia y la práctica especializada de los médicos residentes. Si a esto sumamos la ausencia de programas académicos uniformes, pues cada facultad de medicina tiene el suyo para cada especialidad, entonces tenemos formaciones de especialistas muy disímiles en forma y contenido.

Por otro lado, cada institución prestadora de servicios de salud pertenece a una dirección diferente tal que la suscripción de acuerdos con CONAREME puede verse dificultada toda vez que dichos acuerdos se contrapongan a lo estipulado en sus propios estatutos y reglamentos. Así, las dependencias del MINSA pertenecen al Ministerio de Salud, las de EsSalud al Ministerio de Trabajo, las de las Fuerzas Armadas al Ministerio de Guerra, las de las Fuerzas Policiales al Ministerio del Interior y las clínicas particulares a sus propios directorios.

\section{Fortalezas}

- Dirección centralizada del sistema de residentado médico: SINAREME, CONAREME.

- Una Ley y un Reglamento que sustentan el residentado médico en el país.

- Examen único (EXUN) para acceder al residentado. Inicialmente, cada facultad de medicina realizaba su concurso de admisión y tomaba su respectivo examen. Este examen ha sido centralizado y es organizado y dirigido por CONAREME. 
El examen se toma en cinco sedes de macrorregiones, donde se concentran los postulantes de las diferentes facultades de medicina: Norte (Universidad Nacional de Trujillo), Sur (Universidad Católica Santa María de Arequipa) y Centro (Universidad Ricardo Palma, Universidad Nacional Mayor de San Marcos y Universidad San Martín de Porres).

- Nomenclatura única de las especialidades y subespecialidades. En efecto, en la Asamblea General Ordinaria del 30 de noviembre de 2018, se tomó el Acuerdo $\mathrm{N}^{\circ}$ 059-CONAREME-2018-AG, y oficializado mediante Resolución del Consejo Nacional $\mathrm{N}^{\circ}$ 006-2018-CONAREM E del 3 de diciembre de 2018, por el cual se aprobó la estandarización de las nomenclaturas de 46 especialidades y 40 subespecialidades a ser empleadas por las universidades formadoras del Sistema Nacional del Residentado Médico, a partir del Concurso Nacional de Admisión al Residentado Médico del año 2019

\section{Debilidades}

- Heterogeneidad de los programas académicos del Residentado, en contenido y duración. El contenido y la duración del entrenamiento de cada especialidad deberían estar sustentados por las competencias que el médico residente debe adquirir durante el residentado. Desarrollar programas académicos similares uniformizaría el contenido de lo aprendido durante el entrenamiento de los residentes y la duración de dicho entrenamiento.

- Desigualdad de la infraestructura y facilidades docentes de los campos clínicos. No todos los hospitales cuentan con el equipamiento de laboratorio, imágenes, tecnología, etc., para el ejercicio de determinadas especialidades que la medicina moderna exige. Esto genera obligadas rotaciones externas, incluso al exterior, lo cual es beneficioso en la formación del residente, pero estas rotaciones no siempre suplen ni completan el entrenamiento que se espera que tenga el residente.

- Excesivo número de facultades de medicina. Actualmente, tenemos 46 facultades de medicina en el país y esto va en detrimento de la calidad de la formación del estudiante de pregrado y, por ende, del estudiante de posgrado. Esta deficiente formación se reflejará como bajo rendimiento del residente, en las renuncias al residentado, mala praxis, comportamiento reñido con la ética y deontología médica, etc.

- Falta de concordancia entre CONAREME y ASPEFAM. Estas instituciones marchan casi de manera paralela y excluyente no obstante que las facultades de medicina están representadas en la primera.

- Falta de tutores capacitados en docencia superior. Una parte importante de los médicos que se comprometen en la docencia médica del posgrado, y del pregrado también, no tiene la preparación para ejercer tal docencia. Esto es, no tienen estudios de docencia superior, llámense cursos, diplomados o maestrías, por lo que el uso de recursos pedagógicos es limitado. Muchos lo hacen bien de manera empírica; pero lo ideal es que quien ejerce la docencia se haya preparado para tal trabajo. Ser un buen especialista no basta, no asegura que sea un buen profesor. Solo hay tres facultades de medicina que tienen una unidad de docencia superior.

- La exigencia de competencias para lo cual no han sido preparados. Este es el caso de la investigación científica médica. El residentado médico es un entrenamiento a tiempo completo académico y asistencial. Los médicos residentes no son preparados ni tienen tiempo para dedicarse a la investigación. La gran mayoría de los residentes, una vez titulados, se va a dedicar a la práctica médica asistencial, por lo que era un contrasentido exigirles un trabajo de investigación para titularse. Por otro lado, son muy pocos los tutores que realizan investigación y menos puede exigírsele a los residentes que lo hagan. Lo que deben hacer las facultades de medicina es crear los espacios e incentivos, con los profesores investigadores, para incorporar a aquellos residentes interesados en dedicarse a la docencia e investigación, pero no exigirles a todos como requisito para la titulación. Esta exigencia creó un exceso de médicos residentes que habían terminado el entrenamiento pero no se habían titulado. Esto ha mejorado al cambiarse la exigencia mencionada, en marzo del 2017 con la Ley N 30453 del Sistema Nacional de Residentado Médico (SINAREME), por tan solo la presentación de un proyecto de investigación en lugar del trabajo.

- Discordancia generacional. La población universitaria actual nació entre 1993 y 2010, es la llamada generación Z. Esta generación ha nacido y se ha formado con elementos que antes no existían, con herramientas tecnológicas (computadoras, laptops, tablets, smartphones, etc.) y medios de comunicación (internet, redes sociales, videoconferencias, etc.) que son usados en la docencia pero que sus profesores no usaron. Muchas veces, esta discordancia genera conflictos en el proceso de enseñanza-aprendizaje por lo que es necesario que los tutores se capaciten en docencia superior.

- Mal uso de la jerarquía académica. Muchas veces, por supuestas o reales faltas, los residentes de los primeros años son "castigados" por los tutores o residentes de años superiores con guardias extras no pagadas, horas extras de trabajo, no programación en sala de operaciones, etc. Esto lleva a situaciones lindantes con el abuso o maltrato y que son un motivo de renuncia del residente afectado. Esto se evitaría si cualquier falta cometida por el residente fuera contemplada de acuerdo al Reglamento del Residentado Médico.

- Alto índice de renuncias y problemas con los residentes de las plazas cautivas. Esto tiene su razón en la edad de los médicos residentes (Cuadro 4).

Cuánto más edad tenga un residente de plaza cautiva significa que tiene mayores compromisos familiares y laborales en sus locaciones e instituciones originales (jefaturas de servicio, cargos administrativos, etc.), los cuales van a dificultar el cumplimiento de sus obligaciones académicas y asistenciales, y sus relaciones con sus inmediatos superiores del residentado que tienen edades menores. 


\begin{tabular}{|lccc|}
\hline \multicolumn{1}{|c}{ Modalidad } & Cautiva & Destaque & Libre \\
$\begin{array}{l}\text { Edad promedio } \\
\text { (años) }\end{array}$ & 39 & 40 & 31 \\
$\begin{array}{l}\text { Edad mínima } \\
\text { promedio (años) }\end{array}$ & 26 & 30 & 23 \\
$\quad \begin{array}{l}\text { Edad máxima } \\
\text { promedio (años) }\end{array}$ & 62 & 53 & 67 \\
\hline
\end{tabular}

Fuente: CONAREME, agosto de 2019

Cuadro 4. Edad promedio de los postulantes al EXUN según modalidad, período 2013-2019.

- Falta de correspondencia entre la necesidad de especialistas y los centros laborales que empleen a los graduados de plazas cautivas. Una vez que un residente de plaza cautiva termina su entrenamiento, regresa a sus centros de trabajo de origen, que suelen ser del primer o segundo nivel de atención de salud, donde no pueden ejercer como especialistas hasta que son reubicados en una institución de mayor nivel, lo cual muchas veces no sucede con la rapidez deseada.

- Falta de un sistema alterno para la obtención del título de especialista. En el 2004, ASPEFAM implantó una vía alterna para titularse como especialista: La modalidad de titulación por la evaluación de competencias. En el 2013, esta modalidad se actualizó por el Acuerdo de ASPEFAM No 46-AG-ASPEFAM2013 del 14 de diciembre del 2013. Este acuerdo estuvo vigente hasta mediados de setiembre del 2016 en que fue suspendido por la Superintendencia Nacional de Educación Superior Universitaria (SUNEDU) porque su obtención no está contemplada en la actual Ley Universitaria.
Actualmente, existe cierta presión por aquellos médicos que han ejercido determinada especialidad durante muchos años, especialmente en las provincias, y que necesitan un título de especialista ya que este es un requisito para ser nombrado, promovido u ocupar cargos administrativos. La titulación por la evaluación de competencias satisfacía en parte esta necesidad. CONAREME se ha comprometido a proponer un marco normativo, de acuerdo a Ley, cuyo fin sería una nueva titulación mediante la evaluación por competencias.

En los capítulos siguientes del presente simposio, se va a tener la oportunidad de conocer, en primer lugar, el desarrollo histórico y la conformación del residentado médico en el país, las principales tendencias en la educación superior médica del posgrado de especialización, el clima de aprendizaje en el posgrado de medicina, la investigación en el residentado y, por último, el uso de las tecnologías de información y comunicación (TICs) en el residentado médico.

Citar como: Pamo-Reyna OG. EI Residentado Médico en el Perú - Introducción. Diagnóstico (Lima). 2019;58(3):117-121.

DOI: 10.33734/diagnostico.v58i3.55

Correspondencia: Oscar G. Pamo-Reyna Correo electrónico: oscar.pamo@upch.pe

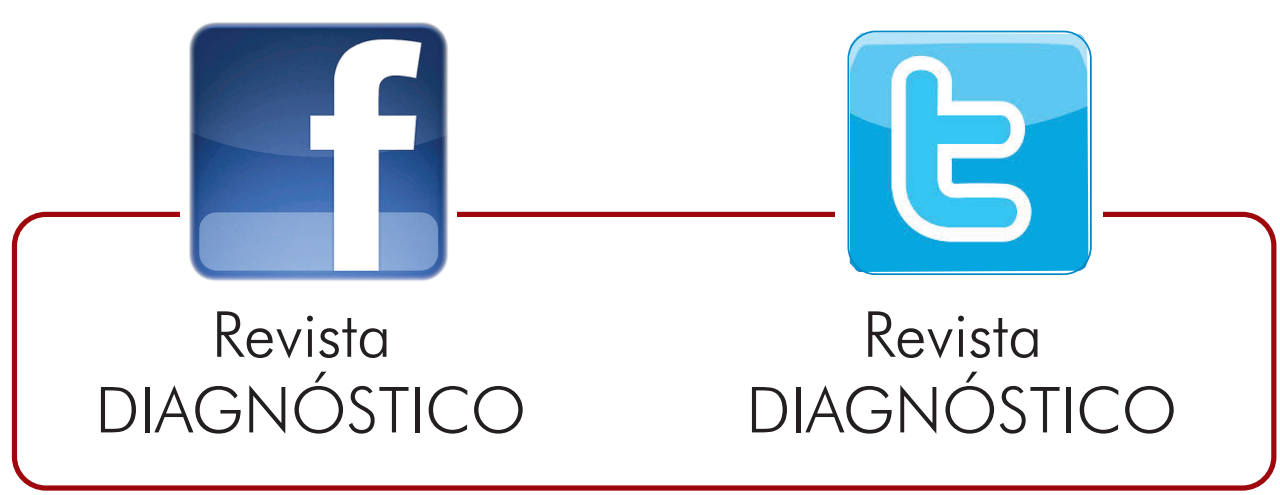

